\title{
Plasmodium vivax malaria relapses at a travel medicine centre in Rio de Janeiro, a non-endemic area in Brazil
}

Renata S Pedro ${ }^{1,2}$, Lusiele Guaraldo ${ }^{1,2}$, Dayse P Campos ${ }^{1}$, Anielle P Costa ${ }^{1,2}$, Cláudio T Daniel-Ribeiro ${ }^{2,3}$ and Patrícia Brasil ${ }^{1,2^{*}}$

\begin{abstract}
Background: Malaria is a potentially severe disease widely distributed in tropical and subtropical regions worldwide. Clinically, the progression of the disease can be life-threatening if it is not promptly diagnosed and properly treated. Through treatment, the radical cure of Plasmodium vivax infection can be achieved, thus preventing potential relapses and the emergence of new cases outside the Amazon region in Brazil. Surveillance for therapeutic failure in non-endemic areas is advantageous, as it is unlikely that recurrence of the disease can be attributed to a new malaria infection in these regions.
\end{abstract}

Methods: An observational study of 53 cases of P. vivax and mixed (P. vivax and Plasmodium falciparum) malaria was conducted at a travel medicine centre between 2005 and 2011 in Rio de Janeiro and a descriptive analysis of the potential factors related to recurrence of $P$. vivax malaria was performed. Groups with different therapeutic responses were compared using survival analysis based on the length of time to recurrence and a set of independent variables thought to be associated with recurrence.

Results: Twenty-one relapses (39.6\%) of P. vivax malaria were observed. The overall median time to relapse, obtained by the Kaplan-Meier method, was 108 days, and the survival analysis demonstrated an association between non-weight-adjusted primaquine dosing and the occurrence of relapse $(p<0.03)$. Primaquine total dose at $3.6 \mathrm{mg} / \mathrm{kg}$ gave improved results in preventing relapses.

Conclusions: A known challenge to individual cure and environmental control of malaria is the possibility of an inappropriate, non-weight-based primaquine dosing, which should be considered a potential cause of $P$. vivax malaria relapse. Indeed, the total dose of primaquine associated with non-occurrence of relapses was higher than recommended by Brazilian guidelines.

Keywords: Plasmodium vivax malaria, Relapse, Therapeutic failure, Weight-based dosing

\section{Background}

Malaria is a potentially severe disease widely distributed in tropical and subtropical regions worldwide. Because of present-day ease of travel and the magnitude of migratory movements, it can be considered a global problem. Death can occur in non-immune

\footnotetext{
*Correspondence: patbr@uol.com.br

'Instituto de Pesquisa Clínica Evandro Chagas (IPEC), Fundação Oswaldo Cruz (Fiocruz), Rio de Janeiro. Av. Brasil 4365. Manguinhos, Rio de Janeiro RJ - CEP 21.045-900, RJ -, Brazil

${ }^{2}$ Centro de Pesquisa, Diagnóstico e Treinamento em Malária (CPD-Mal), Fiocruz and Secretaria de Vigilância em Saúde (SVS), Ministério da Saúde (MS), Brazil

Full list of author information is available at the end of the article
}

individuals if the disease is not diagnosed in time and treated appropriately. Most malaria cases in the Americas occur in Brazil, where Plasmodium vivax is responsible for $84 \%$ of the cases registered, $99.8 \%$ of which occur in the Brazilian Amazon [1-3].

Relapse, a common feature of this type of malaria, is defined as the reappearance of the disease and parasitaemia after initial eradication of blood forms. It is caused by the survival of hypnozoites (dormant forms of P. vivax or Plasmodium ovale latent in the liver) [4]. Although $P$. vivax malaria is known for its benign course, there are reports of more complicated cases in the Brazilian Amazon [5,6] and elsewhere [7,8]. 
Failure in deactivating the hepatic hypnozoite forms of $P$. vivax by treatment can be due to several factors. Although other factors - such as individual pharmacokinetic variations (poor absorption, rapid elimination or low biotransformation of drugs), adherence to the treatment, drug interactions, adverse drug events, dose adjustment to body weight, and treatment duration are directly related to the infection's response to antimalarial treatment, primaquine tolerance is a very important issue that few studies have addressed $[9,10]$.

Detection of treatment failure or relapse may prevent malaria's introduction into unaffected areas where the vector remains a regional menace. As there is no standardized in vitro method for assessing the hypnozoiticidal effects of treatment, patient follow-up - particularly outside the transmission areas - remains the best way to monitor the susceptibility of $P$. vivax to primaquine.

This paper aims to describe the frequency of $P$. vivax malaria relapse at a sentinel unit in a non-Amazonian region and the factors potentially associated with this event.

\section{Methods}

\section{Study design, location, and patient selection}

This descriptive study was conducted from January 2005 to October 2011 at a specialized post-travel care clinic for adolescents and adults ( $\geq 12$ years old) at the Instituto de Pesquisa Clínica Evandro Chagas (IPEC) in Rio de Janeiro, a state located outside the Amazon region and where malaria transmission does not occur.

Eighty-nine patients treated for vivax malaria during the period were studied. Those who had returned to an area of malaria transmission after starting treatment or who had less than 28 days of follow-up were excluded. Accordingly, the analysis contemplated 53 patients (59.6\%). These were followed up for 28 to 408 days (median $=62$ days).

Of the 53 patients studied, $47(88.7 \%)$ were infected only with P. vivax, and the other six (11.3\%), with $P$. vivax and Plasmodium falciparum (mixed malaria). Males predominated (75.5\%), and ages ranged from 14 to 63 years (median $=29$ years). Most of the travellers came from South America: Brazilian Amazon (71.6\%), French Guiana (13.2\%), Venezuela (3.8\%), Guyana (1.9\%) and Suriname (1.9\%); the rest were from Angola (3.8\%) and Indonesia (3.8\%).

Plasmodium vivax infections were treated with chloroquine $(600 \mathrm{mg}$ on the first day, $450 \mathrm{mg}$ on the second and third days) and primaquine. Mixed infections caused by $P$. falciparum and $P$. vivax were treated with mefloquine $(20 \mathrm{mg} / \mathrm{kg}$ body weight, single dose) and primaquine, a therapeutic regimen still used by the Brazilian Malaria Therapy Guidelines until 2009, or with artesunate + mefloquine (200 $\mathrm{mg}+400 \mathrm{mg}$ for three days) and primaquine $[11,12]$. Primaquine was prescribed according to the Brazilian Malaria Therapy Guidelines current at the time of the malaria diagnosis and treatment: (1) total dose of $3.5 \mathrm{mg} / \mathrm{kg}$ or fixed total dose of $210 \mathrm{mg}$ regardless of weight, following the 2001 guidelines [11]; or (2) dose adjusted to stratified patient weight, with total dose ranging from minimal 3.0 to maximal $3.4 \mathrm{mg} / \mathrm{kg}$, following the 2009 guidelines [12]. Over the entire study period, during which both guidelines were used, the total dose of primaquine ranged from 2.2 to $4.9 \mathrm{mg} / \mathrm{kg}$. Primaquine total dose was adjusted in $69.8 \%$ of treatments. Treatment duration varied from 7 to 13 days (short regimen) or from 14 to 28 days (long regimen). A primaquine short regimen was prescribed in most of the treatments (66.0\%) and the remaining patients were treated with primaquine long regimen. The choice of primaquine prescription regimen was made at doctors' discretion at the outpatient clinic. All medicines were prescribed for home use, patients were educated on the importance of following the prescribed regimen exactly and drug administration was not supervised.

The project was approved by the IPEC Research Ethics Committee, Fiocruz (No. 0031.0.009.000-10), and the information obtained was kept strictly secret and confidential.

\section{Detection and quantification of malaria parasites}

Thin and thick blood smears were stained with Giemsa and analysed by light microscopy using an immersion oil lens (x100 objective magnification) to identify the parasite species and determine the density of Plasmodium asexual and sexual stages, according to standard procedures [13]. Malaria smears were examined for diagnosis at each follow-up visit until parasitological clearance and at days 7, 14, 21, 28, 40, and 60 of treatment and at any time in case of fever recurrence.

\section{Data collection}

Data were collected from the clinic and IPEC pharmacovigilance databases. The variables considered were (a) therapeutic response, classified as relapse or nonrelapse; (b) gender; (c) age; (d) adverse drug events; (e) primaquine treatment duration; (f) whether or not the primaquine dose was weight-adjusted; (g) and primaquine total dose. Relapse was considered as the recurrence of parasitaemia following parasitological remission after 28 days from starting treatment for vivax malaria. Primaquine treatment duration was considered an indirect factor related to adherence to treatment, since total dose was the same, regardless of regimen.

\section{Statistical analysis}

Descriptive analysis was performed on factors potentially related to relapse of $P$. vivax malaria. Groups with different therapeutic responses were compared using survival 
analysis. Survival time was defined as the number of days elapsed between starting treatment and disease recurrence. The event of interest was relapse of vivax malaria. Cases with no evidence of relapse during the study period were censored at the last day of followup. The Kaplan-Meier method was applied to calculate the survival functions, which are defined as the probability of relapse not occurring. The log-rank test was used to compare survival functions among categories of each variable. First the hazard ratios (HR) with 95\% confidence intervals were calculated, and then the Cox proportional hazards model. Analysis of Schoenfeld and Martingale residuals was used to assess the Cox method assumptions for covariates of the adjusted model. The smoothing function (spline) was applied for the nonlinear continuous variable "primaquine total dose" in order to show the effect of dose on relapses graphically. Spline coefficient values of less than zero indicate occurrence of protection against relapse. The significance level for all hypothesis testing was set at $\mathrm{p} \leq 0.05$. Data were analysed using R software, version 2.14.2.

\section{Results}

Twenty-one relapses (39.6\%) of P. vivax malaria were observed. Most $(n=14)$ occurred in patients from the Brazilian Amazon; the other patients were from French Guiana $(n=4)$, Venezuela $(n=2)$ and Indonesia $(n=1)$. These relapses occurred in $45.7 \%$ of patients treated with primaquine short regimen $(\mathrm{N}=35)$ and in $28.6 \%$ of patients treated with primaquine long regimen $(\mathrm{N}=14)$ ( $p>0.05)$. Thirty-two cases were censored in survival analysis, because relapse did not occur during the study period (Table 1). All patients with relapse were re-treated. In one case, poor quality primaquine was considered a potential cause of relapse, after more than three relapses occurred in a short period of time. However, quality analysis (physical appearance, content and dissolution) of the chloroquine and primaquine tablets revealed no evidence of poor quality. Time to relapse ranged from 29 to 369 days after start of treatment. In survival analysis, overall median time to relapse obtained by the Kaplan-Meier method was 108.0 days [95\% CI 69 - not achieved], i.e., $50 \%$ of relapses occurred less than 108 days after start of treatment (Figure 1). Patients with adjusted doses of primaquine had higher survival and, consequently, lower relapse rate $(\mathrm{p}<0.03)$ than those with no body weight-based dosing adjustments (Figure 2). The other covariates analysed were not statistically significant (Table 1). The risk of relapse, calculated by the Cox proportional hazards model, was 2.94 times greater [95\% CI 1.09 - 8.33] for patients with no dosing adjustments than for patients with dosing adjustments; and, after adjustment for covariables (gender, age and primaquine treatment duration), estimated risk of relapse were 3.13 [95\% CI 1.08-9.09] (Table 2). Primaquine total dose of $3.6 \mathrm{mg} / \mathrm{kg}$ gave superior results in preventing relapses (protection factor). The probability of relapse not occurring, when primaquine total dose ranged from 3.6 to $4.1 \mathrm{mg} / \mathrm{kg}$, is shown graphically (Figure 3). The increased risk of relapse with primaquine total dose lower than $3.6 \mathrm{mg} / \mathrm{kg}$ in relation to doses ranging from 3.6 to $4.1 \mathrm{mg} / \mathrm{kg}$ was statistically significant. The estimated risk adjusted for covariables was 9.36 [1.06-82.23]. Both Cox proportional hazards models returned strong concordance, with values higher than 70\% (Table 2).

\section{Discussion}

The current study, performed in the city of Rio de Janeiro, where malaria transmission does not occur, showed that approximately $40 \%$ of patients treated within the last six years had relapses of $P$. vivax malaria and that failure to adjust primaquine dosing was the most important factor in the occurrence of relapse. Still, the primaquine total dose related to non-occurrence of relapse was higher than recommended by the Brazilian guidelines. Relapse is considered to be the parasitological recurrence of $P$. vivax after 28 days of treatment in patients who do not return to an endemic area [4]. Nonendemic areas, therefore, offer advantages for monitoring therapeutic failures due to improper treatment or drug resistance since risk of re-infection is minimal or absent.

A retrospective study in São Paulo, Brazil [14] among 1,347 cases of $P$. vivax malaria showed a relapse rate of $25 \%$ over seven years. However, Duarte et al [15] in Cuiaba, Brazil and Kitchener et al [16] in Melbourne, Australia, prospectively followed patients for two years and showed relapse rates of $14 \%$ in 50 patients and $24 \%$ in 318 patients, respectively. The higher frequency recorded $(40 \%)$ could be explained by the smaller sample in this study or by the fact that data for Brazil obtained in 2005-2011 were compared to data obtained in 1991 and in 2003, and concern with primaquine tolerance may have been different in these two periods. The data reported by Kitchener in Australia certainly refer to patients who acquired malaria in quite different localities, and the situations may not be comparable to data obtained in Brazil.

Relapses can occur months or even years after the time of initial infection, with a maximum recorded time of four years [17-20]. In the present study, $86 \%$ of relapses occurred up to day 180 after start of treatment, in agreement with the study by Boulos [14], where 95\% of relapses took place before day 180, and the longest time to relapse (369 days) occurred in a patient with a $P$. vivax infection acquired on a trip to Indonesia, where the prevalence of primaquine-tolerant $P$. vivax is higher than elsewhere [21]. Although there is no standardized or 
Table 1 Patients with $P$. vivax or mixed (P. vivax and $P$. falciparum) malaria treated at IPEC (2005-2011), classified according to therapeutic response

\begin{tabular}{|c|c|c|c|c|c|c|}
\hline & \multicolumn{2}{|c|}{ Non-Relapse } & \multicolumn{2}{|c|}{ Relapse } & \multirow[t]{2}{*}{ Median [Cl 95\%] (days) } & \multirow[t]{2}{*}{ p (Log-Rank } \\
\hline & $\mathbf{n}$ & $\%$ & $\mathbf{N}$ & $\%$ & & \\
\hline Sample & 32 & 100 & 21 & 100 & $108[69-N A\}$ & \\
\hline \multicolumn{7}{|l|}{ Gender } \\
\hline Men & 22 & 68.8 & 18 & 85.7 & 104 [68-NA] & 0.16 \\
\hline Women & 10 & 31.2 & 3 & 14.3 & NA [58-NA] & \\
\hline \multicolumn{7}{|l|}{ Age range (years) } \\
\hline $14-30$ & 14 & 43.8 & 14 & 66.7 & 79 [58-NA] & 0.22 \\
\hline $31-50$ & 13 & 40.6 & 4 & 19.0 & 369 [108-NA] & \\
\hline$\geq 51$ & 5 & 15.6 & 3 & 14.3 & 68 [51-NA] & \\
\hline \multicolumn{7}{|c|}{ Adverse drugs events (ADE)* } \\
\hline Yes & 10 & 31.3 & 2 & 9.5 & NA [58-NA] & 0.20 \\
\hline No & 17 & 53.1 & 12 & 57.1 & 108 [68-NA] & \\
\hline \multicolumn{7}{|c|}{ Duration of primaquine therapy* } \\
\hline Short regimen & 19 & 59.4 & 16 & 76.2 & 79 [65-NA] & 0.34 \\
\hline$\underline{\text { Long regimen }}$ & 10 & 31.3 & 4 & 19.0 & 218 [104-NA] & \\
\hline \multicolumn{7}{|c|}{ Primaquine total dose adjusted by weight* } \\
\hline Yes ( $\geq 3.2 \mathrm{mg} / \mathrm{kg})$ & 25 & 78.1 & 12 & 57.1 & 182 [104-NA] & 0.03 \\
\hline $\mathrm{No}(<3.2 \mathrm{mg} / \mathrm{kg})$ & 5 & 15.6 & 6 & 28.3 & $54[40-N A]$ & \\
\hline
\end{tabular}

* Missing data was $22.6 \%, 7.5 \%$ and $9.4 \%$ for $\mathrm{ADE}$, duration of treatment with primaquine and primaquine dose adjusted by weight, respectively.

$\mathrm{NA}=$ not achieved.

validated method for diagnosing resistance to primaquine [9], the demonstration of primaquine-tolerant P. vivax in the South Pacific, Southeast Asia, Western Pacific, Oceania and Central America [9,10,21,22], associated with travellers' high mobility, should sound an alert to the

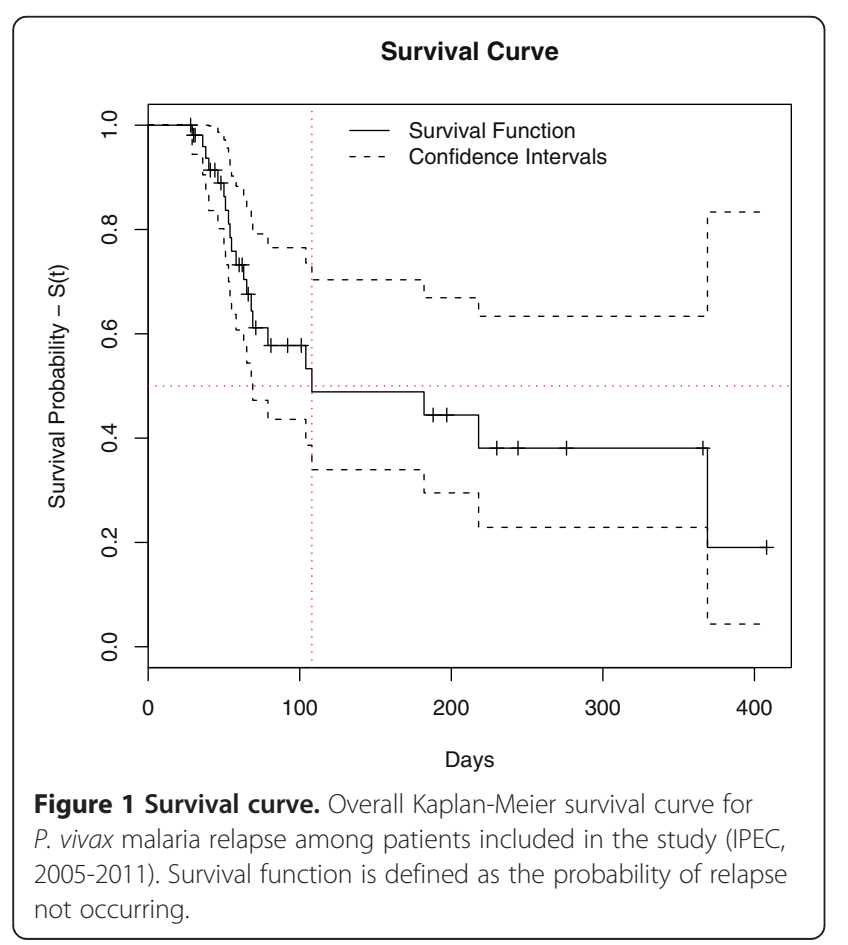

possibility of tolerance being introduced into the Brazilian Amazon [23], from where most relapse cases came.

Besides drug resistance, other factors, such as adherence to the treatment, treatment duration, quality of antimalarials, adverse drug events and dose adjustment to

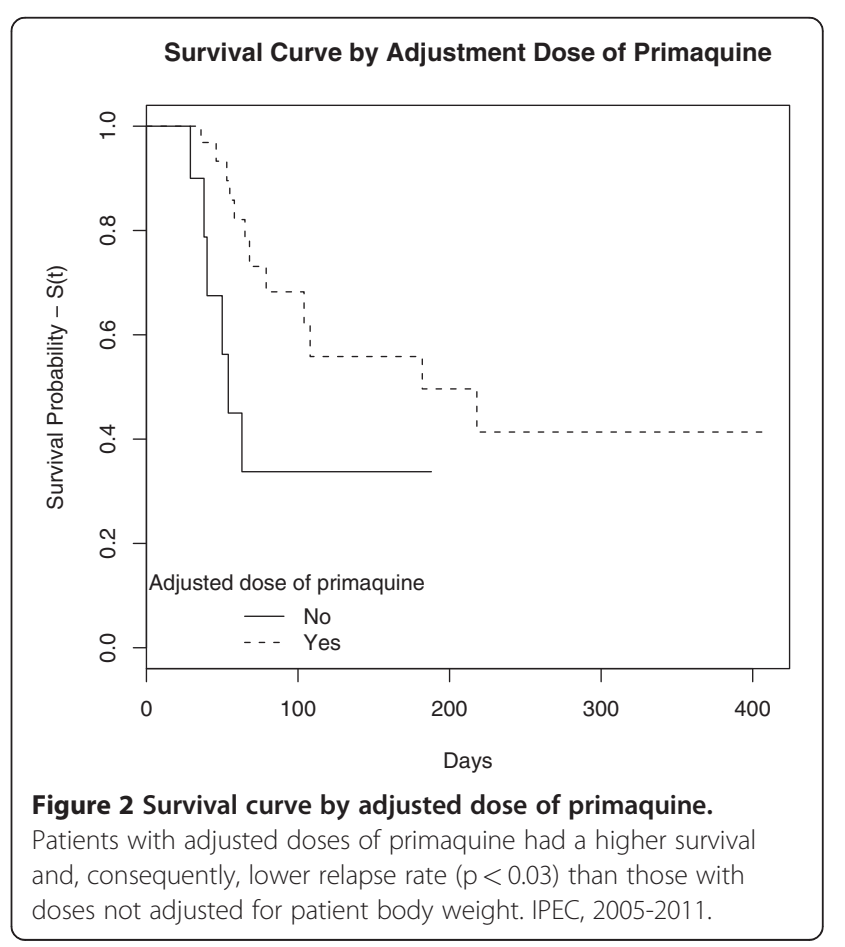


Table 2 Crude and adjusted hazard ratio (HRs) for potential factors related to relapse of $P$. vivax malaria

\begin{tabular}{|c|c|c|c|c|c|c|}
\hline & \multicolumn{2}{|c|}{ Crude $(n=53)$} & \multicolumn{4}{|c|}{ Adjusted* $(n=48)$} \\
\hline & \multirow[b]{2}{*}{$\mathrm{HR}[\mathrm{Cl} 95 \%]$} & \multirow[b]{2}{*}{$p($ Wald $)$} & \multicolumn{2}{|c|}{ Model 1} & \multicolumn{2}{|c|}{ Model 2} \\
\hline & & & HR [Cl 95\%] & $p$ (Wald) & $\mathrm{HR}[\mathrm{Cl} 95 \%]$ & $\mathrm{p}$ (Wald) \\
\hline \multicolumn{7}{|l|}{ Gender } \\
\hline Men & $2.36[0.69-8.07]$ & 0.17 & $2.23[0.63-7.84]$ & 0.21 & 3.9 [0.59-26.81] & 0.16 \\
\hline Women & 1 & & 1 & & 1 & \\
\hline Age (years) ${ }^{* *}$ & $0.97[0.93-1.02]$ & 0.25 & $0.95[0.90-1.01]$ & 0.09 & $0.94[0.89-0.99]$ & 0.03 \\
\hline \multicolumn{7}{|c|}{ Adverse drug events (ADE) } \\
\hline Yes & $0.39[0.09-1.74]$ & 0.22 & - & - & - & - \\
\hline No & 1 & & - & - & - & - \\
\hline \multicolumn{7}{|c|}{ Duration of primaquine therapy } \\
\hline Short regimen & 1 & 0.18 & 1 & 0.14 & 1 & 0.04 \\
\hline Long regimen & $0.46[0.15-1.42]$ & & $0.42[0.13-1.33]$ & & $0.28[0.08-0.98]$ & \\
\hline \multicolumn{7}{|c|}{ Primaquine total dose adjusted by weight } \\
\hline Yes ( $\geq 3.2 \mathrm{mg} / \mathrm{kg})$ & 1 & 0.03 & 1 & 0.04 & - & - \\
\hline No $(<3.2$ mg/kg) & $2.94[1.09-8.33]$ & & $3.13[1.08-9.09]$ & & - & - \\
\hline \multicolumn{7}{|c|}{ Primaquine total dose $(\mathrm{mg} / \mathrm{kg})$} \\
\hline$<3.6$ & $5.24[0.68-40.15]$ & 0.24 & - & - & $9.36[1.06-82.23]$ & 0.04 \\
\hline $3.6-4.1$ & 1 & & - & - & 1 & \\
\hline$>4.1$ & $7.09[0.64-78.74]$ & & - & - & $15.4[0.79-300.57]$ & 0.07 \\
\hline Concordance & - & - & 0.73 & & 0.75 & \\
\hline R square & - & - & 0.23 & & 0.28 & \\
\hline$p$ (Wald) & - & - & 0.06 & & 0.08 & \\
\hline
\end{tabular}

* Cox regression models. ${ }^{* *}$ Continuous variable.

body weight may be related to the infection's response to anti-malarial treatment.

Adherence to anti-malarial treatment remains an important key to malaria control [24,25]. Direct methods (drug serum levels and supervised treatment), and indirect methods (interviews) can quantify adherence to treatment. Although supervision is directly related to treatment effectiveness, health education generally tends to approximate the efficacy of non-supervised and supervised treatments [26,27]. Patients at IPEC are educated on the importance of adherence to regular therapy. This procedure resulted in high adherence behaviour, as previously demonstrated [28] by using Morisky's assessment protocol [29].

Anti-malarials' quality ensures their therapeutic effectiveness in eliminating parasites from the blood and achieving malaria treatment success. Studies performed in Brazil indicate that poor quality anti-malarial drugs and inappropriate storage conditions may contribute to the development of parasite resistance [30,31]. In the present study, poor quality primaquine was suspected as a potential cause of relapse after four relapses in a short time, three of them in one patient, after treatment with the same batch of primaquine [32]. Impaired drug quality was discounted, however, and the patient was successfully treated after adjusting the dose of primaquine.

Most adverse drug reactions were mild and involved disorders of the gastrointestinal system - nausea, vomiting and diarrhoea, which could theoretically have reduced drug absorption. However, in the applied model, relapses were not associated with the occurrence of adverse drug reactions in the study.

Primaquine is currently the only drug available for treatment of the latent liver forms of the parasite. The literature suggests that a 14-day course of primaquine may be more effective than a 7-day course, and this superiority may be attributable to significant accumulation of the drug's active metabolite after longer administration [33-35]. On the other hand, more prolonged treatment may hinder patient adherence, as clinical cure usually occurs in less than 72 hours [28,36]. It seems, however, that this did not occur in the current study, since the proportion of relapses after long-regimen treatment was lower than after the short regimen $(\mathrm{p}>0.05)$ and patient adherence rates were high [28].

Conversely, the results clearly indicate an association between non-weight-based primaquine dosing and the occurrence of relapses $(p<0.03)$. These results agree with studies that suggested dosing adjustments for patients 


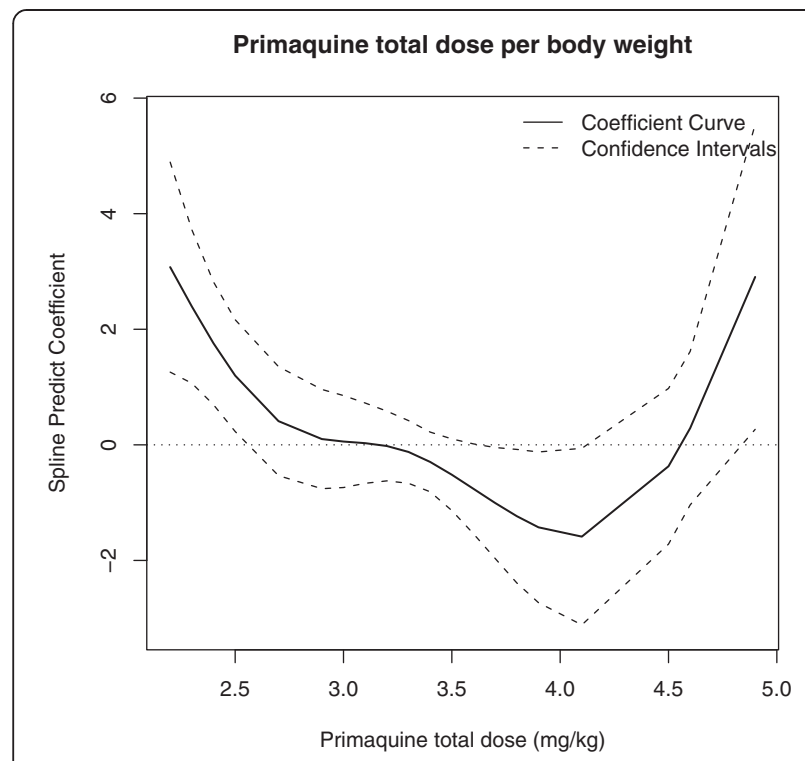

Figure 3 Smoothing function (spline) for primaquine total dose by weight. Primaquine total dose ranging from 3.6 to $4.1 \mathrm{mg} / \mathrm{kg}$ seems to offer protection against relapse.

weighting over $70 \mathrm{~kg}$ at a time when obesity was not yet a global problem [37-40].

Although it is already known that weight-based dosing of primaquine is required to prevent relapses, it is important that an appropriate weight-based primaquine total dose be determined and confirmed to guide clinical decisions. In this study, a total dose of $3.2 \mathrm{mg} / \mathrm{kg}$ indicates protection against relapses. However, the probability of relapse occurring still exists given the upper limit of the confidence interval. Therefore, in order to treat the patients in this study more effectively, a more appropriate dose would be higher (between 3.6 and $4.1 \mathrm{mg} / \mathrm{kg}$ ) than the one recommended by the Brazilian Ministry Health (from 3.0 to $3.4 \mathrm{mg} / \mathrm{kg}[11,12]$ ). The more effective dose range demonstrated here is also closer to the World Health Organization's recommendation of $3.5 \mathrm{mg} / \mathrm{kg}$ in 14 days for radical cure of vivax malaria [41]. This dose does not apply to individuals infected in countries from Oceania and Southeast Asia, where the total recommended dose is $6.0-7.0 \mathrm{mg} / \mathrm{kg}$ in 14 days [42-44]. The increased risk of relapse foreseen by the smoothing function (spline) above $4.1 \mathrm{mg} / \mathrm{kg}$ primaquine total dose by weight, as shown in Figure 3, was not statistically significant.

Although small sample size may be considered a limitation on the statistical analysis, an association was found between adjusted primaquine dose and protection against relapse. Also, follow-up of infected patients in nonendemic areas is a good methodological approach to define a true relapse, because no confounding re-infection is possible in such areas.
The results reported here corroborate the conclusion of Fernando et al [45] that there is enough evidence to support the use of higher total doses of primaquine to prevent relapses in weight-adjusted treatment.

\section{Conclusions}

The study suggests that the total dose of primaquine above which relapses do not occur is $3.6 \mathrm{mg} / \mathrm{kg}$. This conclusion is in agreement with WHO and other international guidelines, but is higher than the total dose recommended by Brazilian Ministry of Health Guidelines. Given the ease of travel, the evidence of growing primaquine tolerance around the world and the possibility of its introduction into the Amazon basin, it would be advisable to review the recommendations of the Brazilian Malaria Control Programme. Finally, it may be argued that malaria control programmes should use public health educational messaging campaigns to alert travel clinicians to the fact that risk of therapeutic failure can be reduced by tailoring drug therapies individually to each patient.

\section{Competing interests \\ The authors have no conflicts of interest to disclose.}

\section{Acknowledgments}

Setor da Garantia da Qualidade e Setor de Farmacovigilância do Instituto de Tecnologia em Fármacos - Farmanguinhos/Fiocruz for drug analysis; Programa de Pós-Graduação do Instituto de Pesquisa Clínica Evandro Chagas - IPEC/Fiocruz; and Seminário Laveran \& Deane for the analysis and criticism of the Master of Science (MSc) project of RSP.

This work is part of RSP's MSc research and was supported by Coordenação de Aperfeiçoamento de Pessoal de Nível Superior (CAPES). CTDR is a Productivity Research Fellowship from the CNPq and a "Cientista do nosso Estado" from Faperj.

\section{Author details}

${ }^{1}$ Instituto de Pesquisa Clínica Evandro Chagas (IPEC), Fundação Oswaldo Cruz (Fiocruz), Rio de Janeiro. Av. Brasil 4365. Manguinhos, Rio de Janeiro RJ - CEP 21.045-900, RJ -, Brazil. ²Centro de Pesquisa, Diagnóstico e Treinamento em Malária (CPD-Mal), Fiocruz and Secretaria de Vigilância em Saúde (SVS), Ministério da Saúde (MS), Brazil. ${ }^{3}$ Laboratório de Pesquisas em Malária. Instituto Oswaldo Cruz, Fiocruz. Pavilhão Leônidas Deane, $5^{\circ}$ andar. Av. Brasil 4365. Manguinhos, Rio de Janeiro, RJ CEP 21.045-900, RJ, Brazil.

\section{Authors' contributions}

RSP: responsible for conception and design of the work, data collection, data analysis, data interpretation and drafting the manuscript. PB: responsible for conception and design of the work, data analysis, data interpretation, literature review and reviewing the manuscript. LG: responsible for conception and design of the work, data analysis, data interpretation, literature review and reviewing the manuscript. DC: responsible for data analysis and interpretation. APC: responsible for data collection and helped to review the text. CTDR: helped in the design of the work and reviewed the text up to the final version to be published. All authors read and approved the final manuscript.

Received: 5 December 2011 Accepted: 16 July 2012 Published: 28 July 2012

\section{References}

1. Oliveira-Ferreira J, Lacerda MVG, Brasil P, Ladislau JLB, Tauil PL, Daniel-Ribeiro CT: Malaria in Brazil: an overview. Malar J 2010, 9:115.

2. Daniel-Ribeiro CT, Lacerda MGV, Oliveira-Ferreira J: Paludisme dû à Plasmodium vivax en Amazonie brésilienne: quelques aspects de son 
épidémiologie, de ses manifestations cliniques et des réactions immunitaires naturellement acquises. Bull Soc Path Exot 2008, 101:243-248.

3. Brasil, Ministério da Saúde: Situação epidemiológica da malária no Brasil, ano de 2007. Brasília: Ministério da Saúde; 2008.

4. Baird JK, Leksana B, Masbar S, Fryauff DJ, Sutanihardja MA, Suradi F, Wignall FS, Hoffman L: Diagnosis of resistance to chloroquine by Plasmodium vivax: timing of recurrence and whole blood chloroquine levels. AmJTrop Med Hyg 1997, 56(Suppl 6):621-626.

5. Costa AP, Bressan CS, Pedro RS, Valls-de-Souza R, Silva S, Souza PR, Guaraldo L, Ferreira-da-Cruz MF, Daniel-Ribeiro CT, Brasil P: Diagnóstico tardio da malária em área endêmica de dengue na extra-Amazônia Brasileira: experiência recente de uma unidade sentinela no estado do Rio de Janeiro. Rev Soc Bras Med Trop 2010, 43:571-574.

6. Lacerda MVG: Manifestações clínicas e patogênses da plaquetopenia na malária. PhD Thesis. Brasília: Universidade de Brasília; 2007

7. Joon Young S, Cheong Won P, You Mee J, Jeong Yun K, Jeong Hyun K, Hyo Joong Y, Chi Hoon K, Chae Seung L, Hee Jin C, Woo Joo K: Two cases of Plasmodium vivax malaria with the clinical picture resembling toxic shock. AmJTrop Med Hyg 2007, 77:609-611.

8. Karyana M, Burdarm L, Yeung S, Kenangalem E, Wariker N, Maristela R, Umana KG, Vemuri R, Okoseray MJ, Penttinen PM, Ebsworth P, Sugiarto P, Anstey NM, Tjitra E, Price RN: Malaria morbidity in Papua Indonesia, an area with multidrug resistant Plasmodium vivax and Plasmodium falciparum. Malar J 2008, 7:148.

9. Baird JK: Resistance to therapies for infection by Plasmodium vivax. Clin Microbiol Rev 2009, 22:508-534.

10. Signorini L, Matteelli A, Castelnuovo F, Castelli F, Oladeji O, Carosi G: Short report: primaquine-tolerant Plasmodium vivax in an Italian traveler from Guatemala. AmJTrop Med Hyg 1996, 55:472-473.

11. Brasil, Ministério da Saúde: Manual de Terapêutica da Malária. Brasília: Ministério da Saúde; 2001.

12. Brasil, Ministério da Saúde: Guia Prático de Tratamento da Malária no Brasil. Brasília: Ministério da Saúde; 2009.

13. Brasil MS: Manual de diagnóstico laboratorial da malária. Brasília: Ministério da Saúde: 2005:112.

14. Boulos M, Amato Neto V, Dutra AP, Di Santi SM, Shiroma M: Análise da freqüência de recaídas de malária por Plasmodium vivax em região não endêmica. Rev Inst Med Trop Sao Paulo 1991, 33:143-146.

15. Duarte EC, Pang LW, Ribeiro LC, Fontes CJF: Association of subtherapeutic dosages of a standard drus regimen with failures in preventing relapses of vivax malaria. AmJTrop Med Hyg 2001, 65:471-476.

16. Kitchener $S$, Nasveld $P$, Bennett $S$, Torresi J: Adequate primaquine for vivax malaria. J Travel Med 2005, 12:133-135.

17. Warrell DA: Clinical features of malaria. In Essential Malariology. 4th edition. Edited by Warrell DA, Gilles HM. New York: Oxford University Press; 2002:192.

18. Fairhurst RM, Wellems TE: Plasmodium species (Malaria). In Mandell, Douglas and Bennett's Principles and Practice of Infectious Diseases. 7th edition. Edited by Mandell GL, Bennett JE, Dolin R. New York: Churchill Livingstone; 2009:3437-3462.

19. Mangoni ED, Severini C, Menegon M, Romi R, Ruggiero G, Majori G: Case Report: an unusual late relapse of Plasmodium vivax malaria. AmJTrop Med Hyg 2003, 68:159-160.

20. White NJ: Determinants of relapse periodicity in Plasmodium vivax malaria. Malar J 2011, 10:297.

21. Schwartz IK, Lackritz EM: Chloroquine resistant Plasmodium vivax from Indonesia. N Engl J Med 1991, 324:927.

22. Rieckmann H, Davis DR, Hutton DC: Plasmodium vivax resistance to chloroquine? Lancet 1989, 334:1183-1184.

23. Ananias LC, Escalante A, Imwong M, Snounou G: The genetic diversity of Plasmodium vivax populations. Trends Parasitol 2003, 19:220-226.

24. Duarte EC, Gyorkos TW: Self-reported compliance with last malaria treatment and occurrence of malaria during follow-up in a Brazilian Amazon population. Trop Med Int Health 2003, 8:518-524.

25. Yeung S, White NJ: How do patients use antimalarial drugs? A review of the evidence. Trop Med Int Helath 2005, 10:121-138.

26. Leslie T, Rab MA, Ahmadzai H, Durrani N, Fayaz M, Kolaczinski J, Rowland M: Compliance with 14-day primaquine therapy for radical cure of vivax malaria - a randomized placebo-controlled trial comparing unsupervised with supervised treatment. Trans R Soc Trop Med Hyg 2004, 98:168-173.
27. Khantikul N, Butraporn P, Kim HS, Leemingsawat S, Tempongko MASB, Suwonkerd W: Adherence to antimalarial drug therapy among vivax malaria patients in Northern Thailand. J Health Popul Nutr 2009, 27:4-13.

28. Pedro RS: Tratamento farmacológico da malária em um instituto de pesquisa clínica no Rio de Janeiro. MSc Thesis. Rio de Janeiro: Fundação Oswaldo Cruz, Instituto de Pesquisa Clínica Evandro Chagas; 2011.

29. Morisky DE, Green LW, Levine DM: Concurrent and predictive validity of a self-reported measure of medication adherence. Med Care 1986, 24:67-73.

30. Nogueira FHA, Moreira-Campos LM, Santos RLC, Pianetti GA: Quality of essential drugs in tropical countries: evaluation of antimalarial drugs in the Brazilian Health System. Rev Soc Bras Med Trop 2011, 44:582-586.

31. Rodrigues LNC, Watanabe SP, Ferraz HG: In vitro dissolution profile of primaquine tablets available for malaria treatment in Brazil. Rev Soc Bras Med Trop 2008, 41:41-45

32. Brasil $P$, Guaraldo L: A importância de uma unidade sentinela de vigilância em malária na região extra-amazônica, referência para viajante. Boletim Farmacovigilância 2007, 4:2

33. Galappaththy GNL, Omari AAA, Tharyan P: Primaquine for preventing relapses in people with Plasmodium vivax malaria. Cochrane Database of Syst Rev 2007, (Issue 1):CD004389. doi:10.1002/14651858.CD004389.pub2.

34. Ward SA, Mihaly GW, Edwards G, Looareesuwan S, Phillips RE, Chanthavanich P, Warrell DA, Orme MLE, Breckenridge AM: Pharmacokinetics of primaquine in man. II. Comparison of acute vs chronic dosage in Thai subjects. Br J Clin Pharmac 1985, 19:751-755.

35. Mihaly GW, Ward SA, Edwards G, Nicholl DD, L'eorme M, Breckenridge AM: Pharmacokinetics of primaquine in man. I. Studies of the absolute bioavailability and effects of dose size. Br J Clin Pharmac 1985, 19:745-750.

36. Muhamad P, Ruengweerayut $R$, Chacharoenkul W, Rungsihirunrat $K$, Na-Bangchang K: Monitoring of clinical efficacy and in vitro sensitivity of Plasmodium vivax to chloroquine in area along Thai Myanmar border during 2009-2010. Malar J 2011, 10:44.

37. Wells TNC, Burrows JN, Baird JK: Targeting the hypnozoite reservoir of Plasmodium vivax: the hidden obstacle to malaria elimination. Trends Parasitol 2010, 26:145-151.

38. Abdon NP, Pinto AYN, Silva RSU, Souza JM: Avaliação da resposta aos esquemas de tratamento reduzidos para malária vivax. Rev Soc Bras Med Trop 2001, 34:343-348.

39. Schwartz E, Regev-Yochay G, Kurnik D: Short report: a consideration of primaquine dose adjustment for radical cure or Plasmodium vivax malaria. AmJTrop Med Hyg 2000, 62:393-395.

40. Santos JB, Luz FCO, Deckers FAL, Tauil PL: Subdoses of primaquine in overweight patients and malaria vivax relapses: report of two cases in the Federal District, Brazil. Rev Soc Bras Med Trop 2010, 43:749-750.

41. World Health Organization: Guidelines for the treatment of malaria. Geneva: WHO; 2010

42. Guidelines for Treatment of Malaria in the United States:: CDC; 2001. http:// www.cdc.gov/malaria/resources/pdf/treatmenttable.pdf.

43. Laloo DG, Shingadia D, Pasvol G, Chiodini PL, Whitty CJ, Beeching NJ, Hill DR, Warrell DA, Bannister BA: UK malaria treatment guidelines. J Infect 2007, 54:111-121.

44. Centre for Disease Control: Malaria guidelines for health professionals in the northern territory. 5th edition. Australia: CDC; 2007.

45. Fernando D, Rodrigo C, Rajapakse S: Primaquine in vivax malaria: an update and review on management issues. Malar J 2011, 10:351

doi:10.1186/1475-2875-11-245

Cite this article as: Pedro et al:: Plasmodium vivax malaria relapses at a travel medicine centre in Rio de Janeiro, a non-endemic area in Brazil. Malaria Journal 2012 11:245 